\section{Association of Colchicine Price and Emergency Department Visits for Gout?}

\section{To the Editor:}

In reading the recent article by Jinno, et $a l^{1}$, I perceive an inflection in the curve for emergency department (ED) visits per 100,000 people in 2009 (Figure 1). This coincides with the US Food and Drug Administration (FDA), Rockville, Maryland, approval of colchicine in July 2009 and the beginning of the manufacturer's campaign to drive competing "unapproved" colchicine from the market. These events may have influenced any of the trends observed. The FDA approval gave Mutual Pharmaceutical Company (later URL Pharma) 3 years of market exclusivity for gout and 7 years of market exclusivity for familial Mediterranean fever. The result was an immediate 50 -fold price increase from about $\$ 0.10$ per tablet to $\$ 5.00$ per tablet $^{2,3}$. I wonder how much the sharp change in cost and availability of colchicine contributed to the increase in ED visits after 2009.
MICHAEL E. MULLINS, MD, FAACT, FACEP, Associate Professor, Emergency Medicine, Washington University School of Medicine, 660 S. Euclid Ave., Campus Box 8072, St. Louis, Missouri 63110-1010, USA.E-mail: mullinsm@wustl.edu

\section{REFERENCES}

1. Jinno S, Hasegawa K, Neogi T, Goto T, Dubreuil M. Trends in emergency department visits and charges for gout in the United States between 2006 and 2012. J Rheumatol 2016;43:1589-92.

2. Kesselheim AS, Solomon DH. Incentives for drug developmentthe curious case of colchicine. N Engl J Med 2010;362:2045-7.

3. Otto MA. Unbranded colchicine getting hard to find [Internet. Accessed December 19, 2016.] Parsippany: Internal Medicine News; 2010. Available from: www.mdedge.com/ internalmedicinenews/article/17288/rheumatology/ unbranded-colchicine-getting-hard-find

J Rheumatol 2017;44:3; doi:10.3899/jrheum.160788

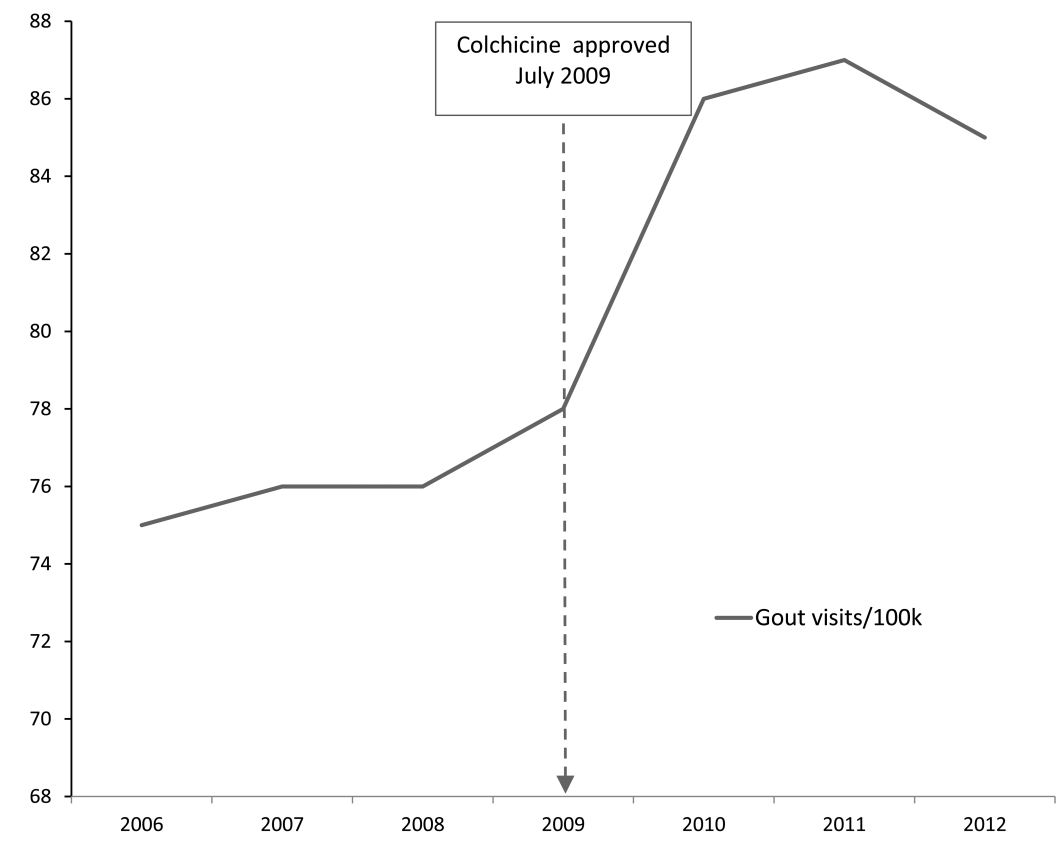

Figure 1. Number of visits to the emergency department for gout per 100,000 people in the United States, 2006-2012. Colchicine was approved by US authorities in 2009. 